\title{
Economic emission dispatch on unit commitment-based microgrid system considering wind and load uncertainty using hybrid MGWOSCACSA
}

\author{
Bishwajit Dey ${ }^{1^{*}} \mathbb{0}$, Biplab Bhattacharyya ${ }^{1}$, Saurav Raj ${ }^{2}$ and Rohit Babu ${ }^{3}$
}

${ }^{*}$ Correspondence:

sonu.aec2007@gmail.com

${ }^{1}$ Department of Electrical Engineering, IIT(ISM),

Dhanbad, India

Full list of author information

is available at the end of the article

\begin{abstract}
Economic emission dispatch (EED) of a three-unit stand-alone microgrid system supported by a wind farm is percolated in this paper. The adverse effects of stochastic and uncertainty nature of wind energy in raising the generation cost of the microgrid system are studied in this article. Unit commitment (UC) of the generating units is taken into account which helps in reducing the generation cost and provides relaxation time to the generation units. Three cases are contemplated for the study. For the first two cases, the generation cost of the test system was minimized without and with the involvement of wind power, respectively. The third case considered the involvement of wind power along with the UC of the conventional generation units. A novel hybrid of recently developed superior optimization algorithms, viz. grey wolf optimizer (GWO), sine-cosine algorithm (SCA) and crow search algorithm (CSA), is implemented to perform EED, and the results are compared with basic GWO and other hybrid algorithms. Results are then analysed to compare and contrast among these cases and justify the reliable and profitable one. Statistical analysis claims the superiority of the proposed hybrid MGWOSCACSA over other hybrids and GWO.
\end{abstract}

Keywords: Microgrid, Uncertainty, Grey wolf optimizer, Sine-cosine algorithm, Crow search algorithm

\section{Introduction}

At a power generating station, the load demand is not sufficed by a single generating entity. Rather, a conglomerate of such entities fulfils the total demand. Moreover, to produce the same amount of power, each unit is incurred with its own cost function (price bid). Economic load dispatch (ELD) works on the fact that not all generating units incur the same amount of cost to suffice same amount of load; rather, same are relatively more costly than others for equal amount of production. So aptly allocating a certain share of the entire demand could actually lower the fuel cost. The total load demand is distributed among various generators which in turn affects the estimation, invoicing, unit commitment and numerous related functions [1]. The total generation of power has to comply with the total current demand. To address this, the ELD could be further categorized

(c) The Author(s) 2020. This article is licensed under a Creative Commons Attribution 4.0 International License, which permits use, sharing, adaptation, distribution and reproduction in any medium or format, as long as you give appropriate credit to the original author(s) and the source, provide a link to the Creative Commons licence, and indicate if changes were made. The images or other third party material in this article are included in the article's Creative Commons licence, unless indicated otherwise in a credit line to the material. If material is not included in the article's Creative Commons licence and your intended use is not permitted by statutory regulation or exceeds the permitted use, you will need to obtain permission directly from the copyright holder. To view a copy of this licence, visit http://creativeco mmons.org/licenses/by/4.0/. 
into two variations depending upon the nature of load demand. The constant load, classical static economic load dispatch (SELD) ignores practical constraints because every load-consuming area does not have a constant all day load demand characteristics, but its nature depends upon the prevalent climatic factors, location and attributes of job undertaken by the inhabitants $[2,3]$. In opposition to this, a dynamic economic load dispatch (DELD) efficiently handles the practical constraint [4]. In DELD, we forecast the demand for the upcoming hours and accordingly distribute the load among different generations to optimize the production. Energy management strategy (EMS) of microgrids falls in DELD category of cost minimization, but is more complicated than SELD. To begin with, microgrid can be imagined as a collection of distributed energy resources (DERs) and loads within a confined geographical area. DERs include fossil-fuelled generators and various renewable energy sources (RES) depending upon the availability of the microgrid location, microturbines, fuel cells, energy storage systems (ESSs) such as battery and flywheel [5]. It is because of the individual modelling and constraints associated with these DERs that economic dispatch of microgrid becomes a complex and cumbersome process for power engineers. Microgrid basically operates in two modes: either islanded or utility-connected [6]. Figure 1a, b depicts the two different working modes of a microgrid system. It is quite obvious that the utility-connected mode is more reliable and efficient as the microgrid can sell/buy power from the utility depending upon the surplus/deficit production of power from its DERs. Also utility-connected microgrid can rely on the grid in case one of its DERs fails, thus preventing from an unwanted and major shutdown of the network.

\section{Literature review}

The last decade has witnessed a lot of research in the microgrid energy management area. Matrix real-coded GA (MRCGA) and imperialist competitive algorithm (ICA) were used by the authors in [7] and [8] to minimize the generation cost of a gridconnected microgrid wherein various cases were studied to analyse the capability of algorithms in handling tight operating ranges of DERs, variable loads and fluctuating electricity price. Cuckoo search algorithm (CuSA) yielded better results than PSO and DE when both SELD and DELD were performed by the authors in [9]. An islanded microgrid system was considered for DELD which consisted of 2 wind turbines (WT) to be separately modelled based on wind speed. The authors performed pareto-optimal front-based economic emission dispatch on a utility-connected microgrid system using adaptive modified PSO (AMPSO) in [10] and GAMS in [11]. Optimization results were reported giving maximum weightage to economic and emission dispatch separately, and

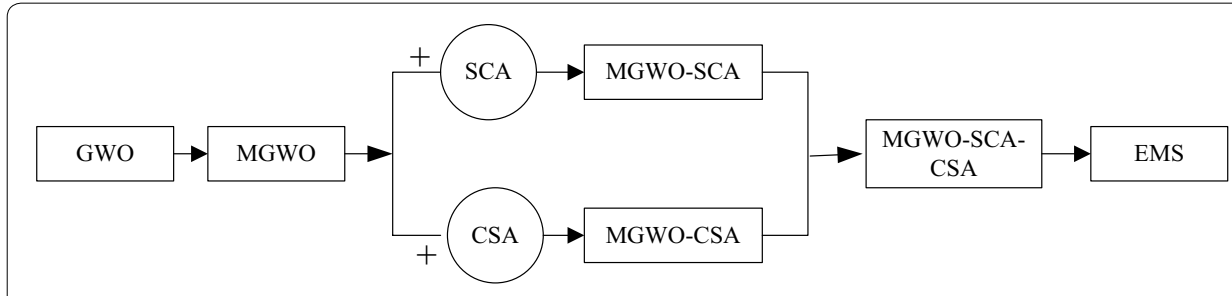

Fig. 1 Block diagram of proposed MGWOSCACSA 
thereafter, a compromised solution emphasizing both the objectives with approximately equal weightage was studied where the proposed algorithms outperformed other optimized techniques studied. The authors in [12] used interior search algorithm (ISA) to perform ELD and price penalty-based combined economic emission dispatch (CEED) on an islanded microgrid powered by three fossil-fuelled generators, a PV and a wind system. These results were again outperformed by modified harmony search algorithm (MHSA) implemented by the author in [13] for the same microgrid system. But the major drawback in these two articles was that the formulation of different types of price penalty factors was not done. Neither any valid reason was mentioned about which type of price penalty factor was chosen to perform CEED. This demerit was attended by the authors in [14] where the various price penalty factors were formulated and calculated, and the least (min-max) penalty factor was chosen to perform CEED. Further, whale optimization algorithm (WOA) provided better quality solutions than other optimization techniques used to evaluate CEED.

The uncertainty study of stochastic behaviour of RES and load demands may be qualitative or quantitative. Various methods exist in the studies to achieve reasonable measure of uncertainty. The system parameters may be uncertain of renewable energies, so neglecting the effect of uncertainty may affect the economic operation or scheduling. Recently, an ample amount of researches which aim to minimize the generation cost or loss of load probability of renewable integrated microgrid systems are seen to conduct probabilistic or uncertainty study on the forecasted load and RES. The authors in [15] have done operation management for interconnected microgrids with proposed hierarchical stochastic energy management system. They confined uncertainty of microgrids and minimized unscheduled power exchange with the main grid considering cost. Optimal sizing of islanded microgrid with demand side management has been done in [16] with developed bi-level algorithm. Battery storage system capacity, lifetime of generators, mixed-integer linear programming unit commitment problem including demand side management and chance constrained have been considered for optimal operation. Frequency may change in microgrid due to the non-smooth character of renewable sources. Optimal solution for battery energy storage system considering uncertainties of wind energy in a microgrid with proposed multi-agent solution has been done in [17], and 14-bus, 30-BESS systems are considered to justify the effectiveness. In [18], two-stage stochastic structure for day ahead scheduling for microgrid has been demonstrated considering real-time electricity price, and uncertainties of wind energy and load demand are considered where price and wind uncertainties are characterized with autoregressive moving-average method. The structure is based on the mixed-integer linear programming, and five case studies have been carried out to validate it. The authors in [19] have implemented proposed expert energy management system (EEMS) for microgrid with wind turbines and other distributed energy resources for optimal operation. Minimization of operation cost and net emission has been minimized. An artificial neural network (ANN) has been used to forecast wind behaviour. Improved bacterial foraging-based fuzzy satisfactory optimization has been used by EEMS for multi-objective problem. In [20], stochastic weight trade-off particle swarm optimization is used to minimize of the operational cost with possibility and probabilistic uncertainties in renewable energy and load demand. To validate the effectiveness, CIGRE LV benchmark microgrid is used 
with fuel cell, diesel generator, wind and solar energy. In [21], simultaneous allocation of distributed energy resources with shunt capacitors considering uncertainty and variability is done under load demand and power generation for distribution system. The authors in [22] optimized the economic operation of small-scale energy zones. Hence, imperialist competitive algorithm is used applied to solve the problem under uncertainties of load and renewable power generation. Electric vehicles are used to serve the load at pick time as demand curve modification in [23]. Responsive load is used to serve required grid reserve for compensate wind and PV uncertainties. The authors in [24] used a novel probability-weighted robust optimization (PRO) for the allocation of DG units with wind turbines in microgrid systems to maximize total profit. The uncertainties have been modelled in probability-weighted uncertainty sets to take the uncertainties into account and developed modified column-and-constraint generation (C\&CG) algorithm to solve the PRO problem. Optimal scheduling of island microgrid under the high penetration of wind and PV has been done in [25] by a two-stage robust model predictive control (RMPC)-based optimization approach. All uncertainties (wind, PV, load demand, water demand) have been considered and obtained. In [26], wind speed forecasting is applied to monitor wind speed. Afterwards, by applying this control method on wind turbine, harvested energy from ultra-capacitor energy storage and wind turbine is increased, and apart from this, the condition of microgrid is improved.

Metaheuristic swarm intelligence algorithms have always been prioritized over classical optimization techniques for solving dynamic EED and EMS problems. This is primarily due to the fact that such problems have exponential and trigonometric terms in their equations which make the problem multimodal and not feasible to be solved by the classical optimization tools. Hybrid and modified metaheuristic algorithms are improvised with logical alterations or exhibit the nature of the various algorithms involved to amalgamate and form the hybrid. This is the reason that hybrid and/or modified optimization techniques yield better quality solutions than the original one. Extensive literature review shows less implementation of hybrid algorithms to solve EED or EMS problems. Recently developed algorithms like GWO, SCA and CSA have already established their superiority in solving optimization problems in various fields. Some of the modification and hybridization done with these three algorithms are listed below along with their year of publication.

\begin{tabular}{|c|c|c|c|}
\hline $\begin{array}{l}\text { Name of the modified/hybridized } \\
\text { algorithm }\end{array}$ & Strategy of modification/hybridization & Year & References \\
\hline Modified grey wolf optimization & $\begin{array}{l}\text { Exploration capability of GWO increased by } \\
\text { involving all classes of wolves }\end{array}$ & 2018 & {$[27]$} \\
\hline Memory-based grey wolf optimizer & $\begin{array}{l}\text { Search mechanism of the wolves is modified } \\
\text { based on the personal best history of each } \\
\text { individual wolves, crossover and greedy } \\
\text { selection }\end{array}$ & 2020 & {$[28]$} \\
\hline Random walk grey wolf optimizer & $\begin{array}{l}\text { Random walk is incorporated in which step } \\
\text { size is drawn from a Cauchy distribution } \\
\text { helpful for the leading wolves to explore } \\
\text { the search space for finding prey }\end{array}$ & 2019 & {$[29]$} \\
\hline
\end{tabular}




\begin{tabular}{|c|c|c|c|}
\hline $\begin{array}{l}\text { Name of the modified/hybridized } \\
\text { algorithm }\end{array}$ & Strategy of modification/hybridization & Year & References \\
\hline $\begin{array}{l}\text { Modified sine-cosine algorithm with novel } \\
\text { transition parameter and mutation opera- } \\
\text { tor }\end{array}$ & $\begin{array}{l}\text { Nonlinear transition rule is introduced to } \\
\text { provide comparatively better transition } \\
\text { from the exploration to exploitation, and } \\
\text { search equation of the SCA is modified by } \\
\text { introducing the leading guidance based } \\
\text { on the elite candidate solution }\end{array}$ & 2020 & [30] \\
\hline Sine-cosine grey wolf optimizer & $\begin{array}{l}\text { Exploration ability of the SCA is improved } \\
\text { by integrating the social and cognitive } \\
\text { component, and the balance between } \\
\text { exploration and exploitation is maintained } \\
\text { through GWO }\end{array}$ & 2020 & [31] \\
\hline Hybrid crow search algorithm & $\begin{array}{l}\text { The merits of the CSA and rough searching } \\
\text { scheme intensify the search in the promis- } \\
\text { ing region where the global solution } \\
\text { resides }\end{array}$ & 2018 & [32] \\
\hline Chaotic crow search algorithm & $\begin{array}{l}\text { Chaotic theory is introduced to tune the } \\
\text { parameters of the standard CSA }\end{array}$ & 2018 & [33] \\
\hline $\begin{array}{l}\text { Multi-objective orthogonal opposition- } \\
\text { based crow search algorithm }\end{array}$ & $\begin{array}{l}\text { Multi-orthogonal opposition strategy is } \\
\text { employed to mitigate the conflicts among } \\
\text { the convergence and distribution of solu- } \\
\text { tions. First, two individuals are randomly } \\
\text { chosen to undergo the crossover stage } \\
\text { and then orthogonal array is presented } \\
\text { to obtain nine individuals. Then individu- } \\
\text { als are used in the opposition stage to } \\
\text { improve the diversity of solutions }\end{array}$ & 2020 & [34] \\
\hline $\begin{array}{l}\text { Hybrid sine-cosine algorithm with multi- } \\
\text { orthogonal search strategy (MOSS) }\end{array}$ & $\begin{array}{l}\text { Integrates the advantages of the SCA and } \\
\text { MOSS to eliminate SCA's disadvantages, } \\
\text { like unbalanced exploitation and the trap- } \\
\text { ping in local optima }\end{array}$ & 2018 & [35] \\
\hline $\begin{array}{l}\text { Improved sine-cosine algorithm based on } \\
\text { orthogonal parallel information }\end{array}$ & $\begin{array}{l}\text { Multiple-orthogonal parallel information } \\
\text { is introduced to exhibit effectively two } \\
\text { advantages: the orthogonal aspect of } \\
\text { information enables the algorithm to } \\
\text { maintain the diversity and enhances the } \\
\text { exploration search, while the parallelized } \\
\text { scheme enables the algorithm to achieve } \\
\text { the promising solutions and empha- } \\
\text { sizes the exploitation search. Further, an } \\
\text { experience-based opposition direction } \\
\text { strategy is presented to preserve the } \\
\text { exploration ability }\end{array}$ & 2019 & [36] \\
\hline $\begin{array}{l}\text { Hybrid harmony search/random search } \\
\text { algorithm }\end{array}$ & $\begin{array}{l}\text { Randomization in HS to drive the system } \\
\text { further to explore various diverse solutions } \\
\text { so as to attain the global optimality }\end{array}$ & 2016 & [37] \\
\hline Hybrid DE-random search approach & $\begin{array}{l}\text { Randomization in DE to drive the system } \\
\text { further to explore various diverse solutions } \\
\text { so as to attain the global optimality and } \\
\text { get rid of demerits such as getting stuck in } \\
\text { local minima }\end{array}$ & 2017 & [38] \\
\hline $\begin{array}{l}\text { Hybrid HS-random search algorithm consid- } \\
\text { ering ensemble and pitch violation }\end{array}$ & $\begin{array}{l}\text { Randomization in HS to drive the system } \\
\text { further to explore various diverse solutions } \\
\text { so as to attain the global optimality }\end{array}$ & 2017 & [39] \\
\hline Hybrid PSO-GWO approach & $\begin{array}{l}\text { Best_Position from PSO acts as search agent } \\
\text { current position and updates the position } \\
\text { of alpha, beta and gamma wolves using } \\
\text { grey wolf optimizer algorithm. Further } \\
\text { alpha position is considered as final posi- } \\
\text { tion of swarms and alpha score as the best } \\
\text { fitness }\end{array}$ & 2016 & [40] \\
\hline HGWO-RES algorithm & $\begin{array}{l}\text { Coordinates the behaviour of grey wolves } \\
\text { based on random exploratory search }\end{array}$ & 2019 & [41] \\
\hline
\end{tabular}




\begin{tabular}{|c|c|c|c|}
\hline $\begin{array}{l}\text { Name of the modified/hybridized } \\
\text { algorithm }\end{array}$ & Strategy of modification/hybridization & Year & References \\
\hline $\begin{array}{l}\text { Hybrid modified grey wolf optimization- } \\
\text { crow search algorithm }\end{array}$ & $\begin{array}{l}\text { Position updating strategy of GWO modified } \\
\text { based on CSA }\end{array}$ & 2019 & [42] \\
\hline $\begin{array}{l}\text { Hybrid algorithm based on grey wolf optimi- } \\
\text { zation and crow search algorithm }\end{array}$ & $\begin{array}{l}\text { Position updating strategy of GWO modified } \\
\text { based on CSA }\end{array}$ & 2020 & [43] \\
\hline $\begin{array}{l}\text { Hybrid modified grey wolf optimization- } \\
\text { sine-cosine algorithm }\end{array}$ & $\begin{array}{l}\text { Hunting strategy of GWO modified incorpo- } \\
\text { rating sine and cosine functions }\end{array}$ & 2019 & [44] \\
\hline Modified crow search algorithm & $\begin{array}{l}\text { Development of crow search algorithm with } \\
\text { an adaptive chaotic awareness probability }\end{array}$ & 2020 & [45] \\
\hline Ameliorated grey wolf optimization & $\begin{array}{l}\text { Coordinates the behaviour of grey wolves } \\
\text { based on random exploratory search, local } \\
\text { random search and opposition learning } \\
\text { heuristics }\end{array}$ & 2019 & {$[46]$} \\
\hline $\begin{array}{l}\text { Improved grey wolf optimizer based on } \\
\text { differential evolution and elimination } \\
\text { mechanism }\end{array}$ & $\begin{array}{l}\text { Wolf pack is updated according to the sur- } \\
\text { vival of fittest principle so as to make the } \\
\text { algorithm not fall into the local optimum }\end{array}$ & 2019 & [47] \\
\hline $\begin{array}{l}\text { Hybrid grey wolf optimizer with mutation } \\
\text { operator }\end{array}$ & $\begin{array}{l}\text { GWO has been hybridized with differential } \\
\text { evolution (DE) mutation }\end{array}$ & 2019 & {$[48]$} \\
\hline $\begin{array}{l}\text { Improved sine-cosine algorithm with crosso- } \\
\text { ver scheme }\end{array}$ & $\begin{array}{l}\text { Improves the SCA using crossover and } \\
\text { personal best memory of agents }\end{array}$ & 2019 & [49] \\
\hline $\begin{array}{l}\text { Hybrid self-adaptive sine-cosine algorithm } \\
\text { with opposition-based learning }\end{array}$ & $\begin{array}{l}\text { Self-adaptive component is added to exploit } \\
\text { all the promising search regions which are } \\
\text { previsited, and opposition-based learning } \\
\text { is incorporated to increase convergence } \\
\text { speed }\end{array}$ & 2019 & [50] \\
\hline A memory-guided sine-cosine algorithm & $\begin{array}{l}\text { The number of memory guides decreased } \\
\text { with the increase in the number of } \\
\text { iterations to provide a sufficient balance } \\
\text { between exploration and exploitation }\end{array}$ & 2020 & [51] \\
\hline Opposition-based grey wolf optimization & $\begin{array}{l}\text { Opposition-based learning is incorporated } \\
\text { to increase convergence speed of GWO }\end{array}$ & 2018 & {$[52]$} \\
\hline
\end{tabular}

\section{Contribution and motivation}

(i) Why choose GWO, SCA and CSA With the aim of performing energy management strategy (EMS) or as in this article EED on microgrid systems, the choice of an efficient and least time-consuming optimization technique was a matter of concern to deal with. Extensive literature survey clearly shows that the use of hybrid optimization techniques is not that prominently used to perform EMS on microgrid systems. Some recently developed algorithms like GWO, sine-cosine algorithm (SCA) and crow search algorithm (CSA) have already proved their superiority and strength in handling engineering problems of larger dimension and complex constraints for optimization. Where GWO is known for a rigorous search within its large search space, SCA is expert in switching between sine and cosine functions to maintain a proper balance between exploration and exploitation. CSA can handle large population size and delivers better results faster than many other algorithms without getting lost in local minima. Summing up these benevolent properties of the three above-mentioned optimization tools, the major contribution of this article can be pictorially demonstrated as shown in Fig. 1. Furthermore, GWO, in order maintain its extensive depth of exploration within its search space, has many stages and equations to follow within every iteration. So to make an efficient hybrid, we would need some algorithms with least amount of governing equations and tuning parameters. Both SCA and CSA have only one conditional governing 
equation and have proved their superiority in solving many engineering optimization problems as seen in the literature. Hence, this paper amalgamates a modified GWO (MGWO) with SCA and CSA to form one hybrid MGWOSCACSA to perform economic and emission dispatch.

(ii) The uncertainty approach Recent trend of all sorts of power system problems such as microgrid energy management problems, optimal power flow problems and reactive power planning problems have witnessed the compelled usage of renewable energy sources. This is primarily due to the depletion of fossil fuels. No matter how available and abundant the renewables may be, they come with the harshest demerit of not being able to controlled or harnessed. Due to their stochastic nature, the day ahead forecasting of power to be gathered from any renewable energy source is just a probabilistic value. In a nutshell, any kind of evaluation and speculation done considering the power output from a renewable source are incomplete without considering the uncertainty approach. This approach gives a valid, though probabilistic range, within which the evaluated and calculated value may lie if and when renewables are considered. Among many such complex simulations available to calculate the uncertainty, this paper proposes a simple way to calculate the uncertainty in the forecasted values of load demand, wind and PV output.

The major contributions of this paper are listed as follows:

(a) Dynamic EED is performed on a three-unit test system using novel hybrid MGWOSCACSA

(b) Three cases are studied while performing dynamic EED, viz. without wind, with wind and with wind and UC of generation units

(c) Generation cost is evaluated considering both forecasted and uncertainty in load and wind profile for the cases.

(d) Proposed MGWOSCACSA was compared with other hybrid algorithms available in the literature, and statistical analysis is carried out.

\section{Paper organization}

Section II formulates the fitness function to be minimized including the equality and inequality constraint. The optimization algorithms used are elaborated in Section III. Section IV deals with the case studies of the subject microgrid test system and performs the statistical analysis and solution quality check of the results obtained. Section V concludes the paper.

\section{Objective function formulation}

The economic emission cost function includes the carbon tax and fuel cost incurred on the fossil fuel generators throughout the day and is represented mathematically as:

$$
F\left(P_{\mathrm{g}}\right)=\sum_{t=1}^{24} \sum_{g=1}^{n g}\left(C_{\mathrm{g}}^{c t}+C_{\mathrm{g}}^{f}\right) * P_{\mathrm{g}}^{t} ; \quad \forall g=1,2,3, \ldots, n g
$$


where $g=1,2,3, \ldots n g s$ and $t=1,2,3, \ldots 24$ are the total number of DERs and hours of operation, respectively. $P^{\mathrm{t}}$ is the power output of the DER at $t$ th hour. $C^{\mathrm{ct}}$ and $C^{\mathrm{f}}$ are the penalized emission cost and fuel cost of the gth generator, respectively.

$$
\begin{aligned}
& \text { Where } P_{\mathrm{g}}=a_{\mathrm{g}} * P_{\mathrm{g}}^{2}+b_{\mathrm{g}} * P_{\mathrm{g}}+c_{\mathrm{g}} \\
& C_{\mathrm{g}}^{c t}=\mathrm{CO}_{2 W} * \mathrm{CO}_{2 T} \\
& \mathrm{CO}_{2 W}=\frac{c c * P_{\mathrm{g}}}{1016.04} \\
& \mathrm{CO}_{2 T}=\frac{P_{\mathrm{TRC}}}{c c} * 1016.04
\end{aligned}
$$

where $C_{\mathrm{g}}^{c t}$ is the penalized emission cost, $\mathrm{CO}_{2 W}$ is the carbon weight in ton, $\mathrm{CO}_{2 T}$ is the carbon tax $(\$ / \mathrm{kg}), P_{\mathrm{g}}$ is the generation, cc is the carbon content $(\mathrm{kg} / \mathrm{kWh})$ and $P_{\text {TRC }}$ is the price of the tradable renewable energy certificate $(\$ / \mathrm{kWh})[53,54]$.

\section{Uncertainty modelling}

Uncertainty modelling is a probabilistic and futuristic predictive study to evaluate the maximum deviation that can be realized by forecasted data especially considering the stochastic and uncontrollable nature of renewable energy sources and load demands. In this paper, the uncertainty modelling of forecasted values of load demand and wind power is done as follows $[54,55]$ :

$$
\begin{aligned}
L_{\mathrm{un}}^{t} & =\mathrm{d} L_{\mathrm{un}} * n_{1}+L_{\mathrm{fc}}^{t} \\
\mathrm{~d} L_{\mathrm{un}} & =0.6 * \sqrt{L_{\mathrm{fc}}^{t}}
\end{aligned}
$$

where $\mathrm{d} L_{\text {un }}$ is the deviation of the load, $L_{\text {un }}^{t}$ is the load demand considering the uncertainty, $n_{1}$ is defined by a standard normal distribution function and $L_{\mathrm{fc}}^{t}$ is forecasted load demand.

$$
\begin{aligned}
& W_{\mathrm{un}}^{t}=\mathrm{d} P_{\mathrm{w}} * n_{2}+W_{\mathrm{fc}}^{t} \\
& \mathrm{~d} P_{\mathrm{w}}=0.8 * \sqrt{W_{\mathrm{fc}}^{t}}
\end{aligned}
$$

where $W_{\mathrm{un}}^{t}$ is uncertainty of wind, $\mathrm{d} P_{\mathrm{w}}$ is deviation of wind power and $n_{2}$ is standard normal distribution function.

\section{Wind deviation and penetration}

$W_{\text {mean }}$ is the hourly mean values of wind obtained from the different scenarios of hourly wind output gathered from a particular location. It is normally close to the values of $W_{f c}$.

$$
W_{\text {mean }}^{t}=\frac{\sum_{d=1}^{D} W_{d}^{t}}{D}
$$

Wind power deviation (\%) measures the amount of hourly deviation (or the difference) of both the mean and uncertainty values of wind from the forecasted value. 


$$
\text { Deviation } \%=\frac{W_{\mathrm{fc}}^{t}-W_{\text {mean } / \mathrm{un}}^{t}}{W_{\mathrm{fc}}^{t}} * 100
$$

Wind penetration (\%) is the ratio of amount of load demand shared by the wind power to the total load demand throughout the day.

$$
\text { Penetration } \%=\frac{\sum_{t=1}^{24} W_{f c / d / \text { mean }}^{t}}{\sum_{t=1}^{24} L_{\mathrm{fc}}^{t}} * 100 ; \quad \forall d=1,2, \ldots, D
$$

\section{Division of load}

Many case studies are dependent on the division of load. Here, in this paper we consider two types of load, viz. gross load and net load $\left(L_{\text {net }}\right)$. Gross load is the forecasted load of the system, whereas net load is the load to be shared among the conventional fossilfuelled generators.

$$
L_{\mathrm{net}}=\left\{\begin{array}{l}
L_{\mathrm{fc}} \\
L_{\mathrm{fc}}-W_{\mathrm{fc}} \\
L_{\mathrm{fc}}-W_{\text {mean }} \\
L_{\mathrm{un}}-W_{\mathrm{un}}
\end{array}\right.
$$

\section{Utilization percentage (UP)}

UP marks the participation of the DERs in the sharing of load throughout the day [56]. It is calculated using the formula below:

$$
\mathrm{UP}=\frac{\sum_{t=1}^{24} P_{\mathrm{g}}^{t}}{24 * P_{\mathrm{g}}^{\max }}
$$

\section{Constraints}

The economic emission evaluation function in Eq. (1) is bounded by some constraints mentioned below:

$$
\sum_{t=1}^{24} P_{\mathrm{g}}^{t} * I_{\mathrm{g}}^{t}+P_{w}^{t}=P_{D}^{t}
$$

where $I_{\mathrm{g}}$ is the ON/OFF status of the generator and $P_{\mathrm{D}}$ the load demand during $t$ th hour.

$$
\begin{aligned}
& {\left[X_{\mathrm{g}}^{\text {on }(t-1)}-T_{\mathrm{g}}^{\mathrm{on}}\right] *\left[I_{\mathrm{g}}^{(t-1)}-I_{\mathrm{g}}^{t}\right] \geq 0} \\
& {\left[X_{\mathrm{g}}^{\mathrm{off}(t-1)}-T_{\mathrm{g}}^{\mathrm{off}}\right] *\left[I_{\mathrm{g}}^{t}-I_{\mathrm{g}}^{(t-1)}\right] \geq 0}
\end{aligned}
$$

where $X^{\mathrm{ON} \text { ? OFF }}$ are the ON/OFF time and $T^{\mathrm{ON} \text { ? OFF }}$ are the minimum ON/OFF time of the generators 


$$
P_{g, \min } * I_{\mathrm{g}}^{t} \leq P_{\mathrm{g}}^{t} \leq P_{g, \max } * I_{\mathrm{g}}^{t}
$$

\section{Hybrid grey wolf optimizers}

This paper implements GWO and hybrid MGWOSCACSA for performing EMS on microgrid systems. The mathematical modelling of this hybrid algorithm is established below.

\section{Grey wolf optimizer (GWO)}

GWO [57] mimics the hunting behaviour of the wolves while devouring its prey. A pack of 10-12 wolves maintains a hierarchy among themselves. The leader wolf is said to be alpha $(\alpha)$. It guides the pack, but might not be the strongest in the pack. Next in rank is beta $(\beta)$ whose prime duty is maintaining discipline in the pack and assisting alpha to reach the prey. Delta $(\delta)$ comes third in rank and may be considered as a scapegoat. Rest of all the wolves fall in the omega $(\Omega)$ category and comes last in the pack. In the GWO algorithm, the best three solutions are $\alpha, \beta$ and $\delta$. Rest of the solutions are $\Omega$. The hunting procedure of the wolves can be mathematically represented as:

$$
\left.\begin{array}{l}
\vec{D}_{\alpha}=\left|\vec{C}_{1} \cdot \vec{X}_{\alpha}-\vec{X}\right| \\
\vec{D}_{\beta}=\left|\vec{C}_{2} \cdot \vec{X}_{\beta}-\vec{X}\right| \\
\vec{D}_{\delta}=\left|\vec{C}_{3} \cdot \vec{X}_{\delta}-\vec{X}\right|
\end{array}\right\}
$$

And the position updating procedure of the wolves is given as:

$$
\begin{aligned}
& \vec{X}_{1}=\vec{X}_{\alpha}-\vec{A}_{1} \cdot\left(\vec{D}_{\alpha}\right) \\
& \left.\vec{X}_{2}=\vec{X}_{\beta}-\vec{A}_{2} \cdot\left(\vec{D}_{\beta}\right)\right\} \\
& \vec{X}_{3}=\vec{X}_{\delta}-\vec{A}_{3} \cdot\left(\vec{D}_{\delta}\right) \\
& \vec{X}_{(\mathrm{iter}+1)}=\frac{\vec{X}_{1}+\vec{X}_{2}+\vec{X}_{3}}{3}
\end{aligned}
$$

The value of vectors $A$ and $C$ can be calculated as:

$$
\begin{aligned}
& \vec{A}=2 \cdot \vec{a} \cdot \vec{r}_{1}-\vec{a} \\
& \vec{C}=2 \cdot \vec{r}_{2}
\end{aligned}
$$

Wolves move away from the current prey if absolute value of vector $\mathrm{A}$ is more than 1 and is forcefully pulled towards the prey when absolute value of vector A is more than 1 . ' $a$ ' decreases linearly from 2 to 0 iteration-wise using the formula

$$
a=2 *\left(1-\frac{\text { iter }}{\text { Max_iter }}\right)
$$

\section{Modified GWO}

To eliminate the possibility of the solution getting trapped within the position of the $\Omega$ wolves, the authors in [27] proposed that a few number of $\Omega$ wolves also take part in the 
hunting procedure along with the $\delta$ wolves. The hunting equation will therefore differ from earlier GWO algorithm by:

$$
\left.\begin{array}{r}
\vec{D}_{\alpha}=\left|\vec{C}_{1} \cdot \vec{X}_{\alpha}-\vec{X}\right| \\
\vec{D}_{\beta}=\left|\vec{C}_{2} \cdot \vec{X}_{\beta}-\vec{X}\right| \\
\vec{D}_{\delta}=\left|\vec{C}_{3} \cdot \vec{X}_{\delta}-\vec{X}\right| \\
\vec{D}_{\Omega}=\left|\vec{C}_{4} \cdot \vec{X}_{\Omega}-\vec{X}\right|
\end{array}\right\}
$$

The position updating procedure will be performed including the $\delta$ in the family of wolves as:

$$
\left.\begin{array}{c}
\vec{X}_{1}=\vec{X}_{\alpha}-\vec{A}_{1} \cdot\left(\vec{D}_{\alpha}\right) \\
\vec{X}_{2}=\vec{X}_{\beta}-\vec{A}_{2} \cdot\left(\vec{D}_{\beta}\right) \\
\vec{X}_{3}=\vec{X}_{\delta}-\vec{A}_{3} \cdot\left(\vec{D}_{\delta}\right) \\
\vec{X}_{4}=\vec{X}_{\Omega}-\vec{A}_{4 \cdot\left(\vec{D}_{\Omega}\right)}
\end{array}\right\}
$$

Hereafter, the hybridization will be done with GWO and not GWO as the results of MGWO were obviously found better and promising than GWO.

\section{Sine-cosine algorithm}

The entire process of a stochastic population-based optimization algorithm can be divided into two phases. The first phase is the exploration phase where the random solutions of the fitness function involves very high rate of randomness to broaden the search space and locate the promising region of a superior solution. On the other hand, in the second phase, also called the exploitation phase, the degree of randomness decreases and slow and gradual changes are implemented in the solutions to proceed towards a better quality solution.

The sine-cosine algorithm (SCA) [58] employs these two stages in its governing equation which is:

$$
X_{\mathrm{dim}}^{\mathrm{iter}+1}=\left\{\begin{array}{l}
X_{\mathrm{dim}}^{\mathrm{iter}}+\operatorname{rand}_{1} * \sin \left(\operatorname{rand}_{2}\right) *\left|\operatorname{rand}_{3} * \operatorname{Pos}_{\mathrm{dim}}^{i t e r}-X_{\mathrm{dim}}^{i t e r}\right|, \operatorname{rand}_{4}<0.5 \\
X_{\mathrm{dim}}^{\mathrm{iter}}+\operatorname{rand}_{1} * \cos \left(\operatorname{rand}_{2}\right) *\left|\operatorname{rand}_{3} * \operatorname{Pos}_{\mathrm{dim}}^{i t e r}-X_{\mathrm{dim}}^{i t e r}\right|, \operatorname{rand}_{4} \geq 0.5
\end{array}\right.
$$

where $\mathrm{d}$ is the dimension, $\mathrm{X}$ is the solution and $\mathrm{P}$ is the position of solution from destination point. The random numbers $\operatorname{rand}_{1}, \operatorname{rand}_{2}, \operatorname{rand}_{3}$ and $\operatorname{rand}_{4}$ have their own importance. The direction of the next position whether it lies in between solution and destination or away from both is governed by rand1, whereas rand2 implies how lengthy should be the displacement, be it away from or towards the destination. While 
rand 3 acts as a weightage factor for the destination, the random number rand4 switches between the sine and cosine function.

\section{Crow search algorithm}

Crows possess the habit of observing and follow other birds in order to determine their food storage locations and take their food in their absence. Moreover, if the crow does steal food from another bird, it becomes extra cautious and keeps shifting its own hiding place to avoid becoming a victim of robbery in future. Not only this, it also uses its own knowledge to prevents its food from the robbers. The CSA [59] is based on these behaviours of a crow.

Supposedly at iteration 'iter' crow ' $j$ ' wants to visit its hiding place mem, ${ }^{j, \text { iter }}$. And in the same iteration, say crow ' $i$ ' plans to follow crow ' $j$ '. At this instant, two cases may happen:

Case 1: Crow ' $j$ ' is totally unaware of the fact that it is followed by crow ' $i$, and as a result, crow ' $i$ ' will know the hiding place of crow ' $j$ '.

Case 2: Crow ' $j$ ' knows that it is being followed by crow ' $i$ ' and hence fools crow ' $i$ ' by diverting it to a different random location within the search space.

These two cases can be mathematically represented with a set of equations as:

$$
X^{i, \text { iter+1 }}= \begin{cases}X^{i, \text { iter }}+\operatorname{rand}_{i} \times f l^{i} \times\left(\operatorname{mem}^{j, \text { iter }}-X^{i, \text { iter }}\right) & \operatorname{rand}_{j} \geq A P^{j} \\ \text { any random position } & \text { otherwise }\end{cases}
$$

where randi and randj are random numbers with uniform distribution between 0 and 1 and fli is the flight length of the ith crow. If 'Case 1' occurs, the updating of the memory of crow ' $i$ ' will occur based on the formula below:

$$
\text { mem }^{i, \text { iter+1 }}= \begin{cases}X^{i, \text { iter+1 }} & \text { if } f\left(X^{i, \text { iter+1 }}\right) \text { is better than } f\left(\text { mem }^{i, \text { iter }}\right) \\ \text { mem }^{i, \text { iter }} & \text { otherwise }\end{cases}
$$

$f($.$) denotes the value of the fitness function.$

\section{Modified GWO-SCA-CSA}

Hybrid MGWOSCACSA is the amalgamation of MGWO, SCA and CSA in which the mathematical implications of SCA are done in the hunting method of grey wolves and the strategy of CSA is used to modify the position updating procedure of MGWO as follows:

$$
\begin{aligned}
& \vec{D}_{\alpha}=\operatorname{rand} * \sin (\text { rand }) *\left|\vec{C}_{\alpha} \cdot \vec{X}_{\alpha}-\vec{X}\right| \quad \text { if rand }>0.5 \\
& \left.\vec{D}_{\alpha}=\operatorname{rand} * \cos (\text { rand }) *\left|\vec{C}_{\alpha} \cdot \vec{X}_{\alpha}-\vec{X}\right| \text { otherwise }\right\} \\
& \vec{D}_{\beta}=\operatorname{rand} * \sin (\text { rand }) *\left|\vec{C}_{\beta} \cdot \vec{X}_{\beta}-\vec{X}\right| \quad \text { if rand }>0.5 \\
& \left.\vec{D}_{\beta}=\operatorname{rand} * \cos (\text { rand }) *\left|\vec{C}_{\beta} \cdot \vec{X}_{\beta}-\vec{X}\right| \quad \text { otherwise }\right\}
\end{aligned}
$$




$$
\left.\begin{array}{l}
\vec{D}_{\delta}=\operatorname{rand} * \sin (\text { rand }) *\left|\vec{C}_{\delta} \cdot \vec{X}_{\delta}-\vec{X}\right| \quad \text { if rand }>0.5 \\
\vec{D}_{\delta}=\operatorname{rand} * \cos (\text { rand }) *\left|\vec{C}_{\delta} \cdot \vec{X}_{\delta}-\vec{X}\right| \quad \text { otherwise }
\end{array}\right\}
$$

Thereafter, $X_{1}, X_{2}, X_{3}$ and $X_{4}$ are calculated as shown in Eq. (21). The position updating step of MGWOSCACSA is:

$$
\left.\begin{array}{l}
\vec{X}_{(\text {iter }+1)}=\vec{X}+f l * \text { rand } *\left\{\left(\vec{X}_{1}-\vec{X}\right)+\left(\vec{X}_{2}-\vec{X}\right)+\left(\vec{X}_{3}^{\prime \prime}-\vec{X}\right)\right\} / 3 \quad \text { if } A P>\text { rand } \\
\vec{X}_{(\text {iter }+1)}=\vec{X}+f l * \text { rand } *\left(\vec{X}_{1}-\vec{X}\right) \text { otherwise }
\end{array}\right\}
$$

$A P$ decides whether to consider all the alpha, beta, delta and omega wolves for updation process or to rely on the alpha (leader) wolf only. To reduce the cumbersome task of tuning a parameter, $A P$ which is a probabilistic value changes in every using the formula:

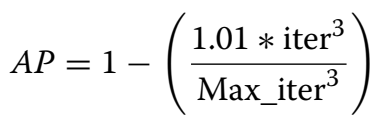

\section{Hybrid MGWO-SCA-CSA}

Initialize the grey wolves population $X_{i}(i=1,2,3, \ldots . N)$

Initialize $a, A$ and $C$

Define Max $_{\text {iter }}=$ maximum number of iterations

Calculate hunting positions $D_{\alpha}, D_{\beta}, D_{\delta}, D_{\Omega}$ using Eq. (26-29)

Evaluate objective function for each search agent

$X_{\alpha}=$ best search agent

$X_{\beta}=$ second best search agent

$X_{\delta}=$ third best search agent

$X_{\omega}=$ remaining search agent

while $\mathrm{t}<\operatorname{Max}_{\text {iter }}$ do

for each search agent do

Perform position updation of the existing search agent by Eq. (30)

end for

Update $a, A$ and $C$

Evaluate objective function for all search agents

Update $X_{\alpha}, X_{\beta}, X_{\delta}$, and $X_{\omega}$

$\mathrm{t}=\mathrm{t}+1$

end while

return $X_{\alpha}$

The pseudocode for proposed hybrid MGWOSCACSA is given below: 


\section{Implementation of hybrid MGWOSCACSA for the microgrid economic emission dispatch problem}

The below-mentioned steps are the guidelines to implement the four algorithms for solving the concerned residential microgrid problem:

Step 1 For $T$ hours of optimal scheduling, $D$ numbers of DERs and $N$ particles of the population, initialize the population matrix as stated in Eq. (32). Each particle of the population consists of $D$ DERs for $T$ hours of scheduling. Hence, the size of every particle is $\left(D^{*} T\right)$ which is also the dimension of the problem. It is to be noted that every particle of the population must abide by the constraints mentioned in Eq. (11) to (14).

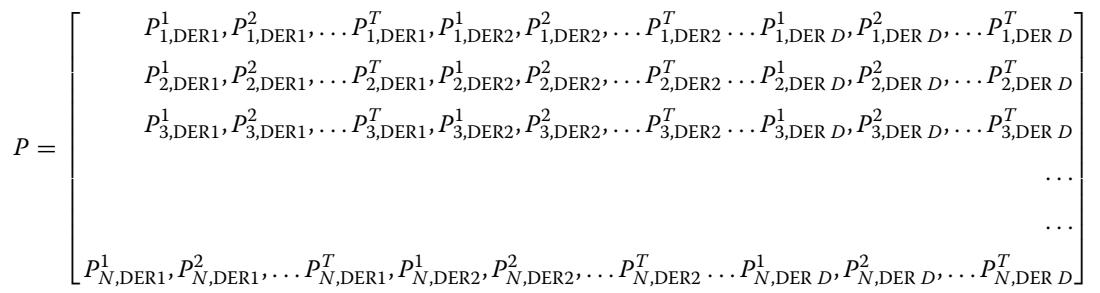

Step 2 Calculate the fitness function for every particle of the population.

Step 3 Initialize the parameters a, A and C using Eq. (18) and (19).

Step 4 Sort the population from best to worst. The best, second best, third best and fourth best particles of the population are ranked as $X_{\alpha}, X_{\beta}, X_{\delta}$ and $X_{\Omega}$.

Step 5 Evaluate the parameters $D_{\alpha}, D_{\beta}, D_{\delta}$ and $D_{\Omega}$ using Eqs. (26-29).

Step 6 Update the position of the particles using Eqs. (30).

Step 7 Check whether all the particles abide by the constraints listed in Eq. (11) to (14).

Step 8 Go to Step 2 until the maximum number of iterations is reached.

\section{Case studies}

Description of the system A six-bus microgrid system was considered for the day ahead economic and emission dispatch study using proposed hybrid MGWOSCACSA. The system is connected with 3 generators and a wind farm as shown in Fig. 2. The optimal scheduling of these DERs is the bottleneck of the concerned economic emission dispatch of the system. Table 1 displays the operating ranges and the uptime of the conventional generators, whereas Table 2 shows the quadratic fuel cost parameters and fuel prices of the conventional fossil-fuelled generators. The hourly load variation and the forecasted value of hourly wind power are mentioned in Table 3 . The forecasted values of wind are inferred to have taken from a single unit and follow a normal distribution with a standard deviation of $10 \%$ [60]. In total, 3000 individual samples of 24-h period wind power were generated using Latin hypercube sampling method, and from there, 10 scenarios were chosen for study [60] (Fig. 3). These scenarios are plotted in Fig. 2. Uncertainty of wind power w.r.t. its forecasted value is calculated, and the mean of the 10 scenarios is calculated using formula mentioned in 
Sect. 2. Forecasted value, mean value and uncertainty value of $24 \mathrm{~h}$ period of wind are plotted in Fig. 4a. Figure $4 \mathrm{~b}$ shows the hourly percentage deviation of the mean values and uncertainty values of wind from the forecasted values. The penetration percentage of various wind scenarios including forecasted, mean and uncertainty is evaluated, and a bar diagram is used to represent these in Fig. 5. Uncertainty of load w.r.t. its forecasted value is calculated and plotted in Fig. 6. The penalized emission cost is taken as $\$ 0.05 / \mathrm{kW}$ for all the generation units. Parameter ' $f l$ ' of proposed hybrid MGWOCSA and MGWOSCACSA is taken as 2.

With these evaluated and predefined data on wind, load and generators, economic emission dispatch was percolated for three different cases and is discussed below:

\section{Case 1: without wind support}

Initially economic and emission dispatch was performed using the proposed MGWOSCACSA and the generation costs were recorded for the forecasted load profile and the uncertainty load profile. The generation cost considering the forecasted load was

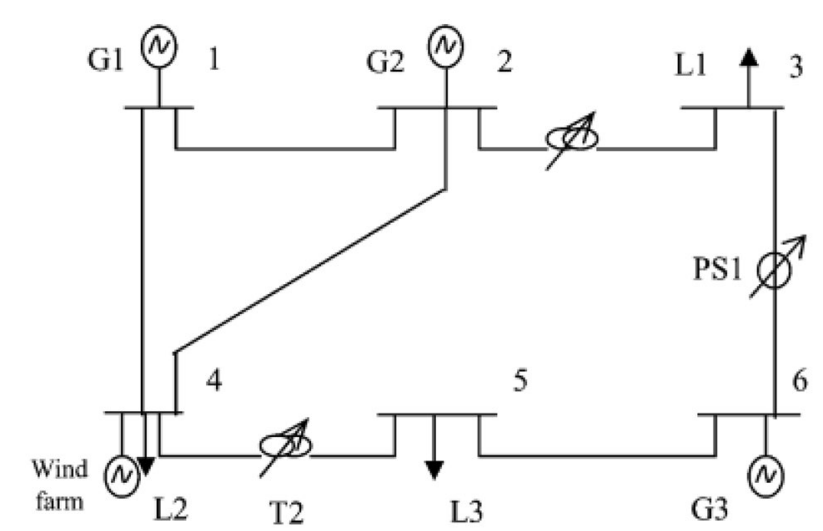

Fig. 2 Six-bus system

Table 1 Generator data

\begin{tabular}{llll}
\hline Unit & $\boldsymbol{P}_{\max }(\mathbf{k W})$ & $\boldsymbol{P}_{\min }(\mathbf{k W})$ & $\begin{array}{l}\text { Min } \\
\text { uptime } \\
\text { (h) }\end{array}$ \\
\hline G1 & & 90 & 10 \\
G2 & 220 & 10 & 10 \\
G3 & 100 & 10 & 10 \\
\hline
\end{tabular}

Table 2 Generator fuel consumption data

\begin{tabular}{|c|c|c|c|c|}
\hline \multirow[t]{2}{*}{ Unit } & \multicolumn{3}{|c|}{ Fuel consumption function } & \multirow[t]{2}{*}{ Fuel price $(\$ / \mathbf{k g})$} \\
\hline & $a\left(\mathrm{~kg} / \mathrm{kW}^{2} \mathrm{~h}\right)$ & $b(\mathrm{~kg} / \mathrm{kWh})$ & $c(\mathrm{~kg})$ & \\
\hline G1 & 0.0004 & 13.5 & 176.9 & 1.2469 \\
\hline G2 & 0.001 & 32.6 & 129.9 & 1.2461 \\
\hline G3 & 0.005 & 17.6 & 137.4 & 1.2462 \\
\hline
\end{tabular}


Table 3 Hourly load and forecasted wind power

\begin{tabular}{llllll}
\hline $\boldsymbol{H}$ & $\boldsymbol{P}_{\mathbf{D}}$ & $\boldsymbol{P}_{\text {Wind }}$ & $\boldsymbol{H}$ & $\boldsymbol{P}_{\mathbf{D}}$ & $\boldsymbol{P}_{\text {- }}$ Wind \\
\hline 1 & 219.19 & 44 & 13 & 326.18 & 84 \\
2 & 235.35 & 70.2 & 14 & 323.60 & 80 \\
3 & 234.67 & 76 & 15 & 326.86 & 78 \\
4 & 236.73 & 82 & 16 & 287.79 & 32 \\
5 & 239.06 & 84 & 17 & 260.00 & 4 \\
6 & 244.48 & 84 & 18 & 246.74 & 8 \\
7 & 273.39 & 100 & 19 & 255.97 & 10 \\
8 & 290.40 & 100 & 20 & 237.35 & 5 \\
9 & 283.56 & 78 & 21 & 243.31 & 6 \\
10 & 281.20 & 64 & 22 & 283.14 & 56 \\
11 & 328.61 & 100 & 23 & 283.05 & 82 \\
12 & 328.10 & 92 & 24 & 248.75 & 52 \\
\hline
\end{tabular}

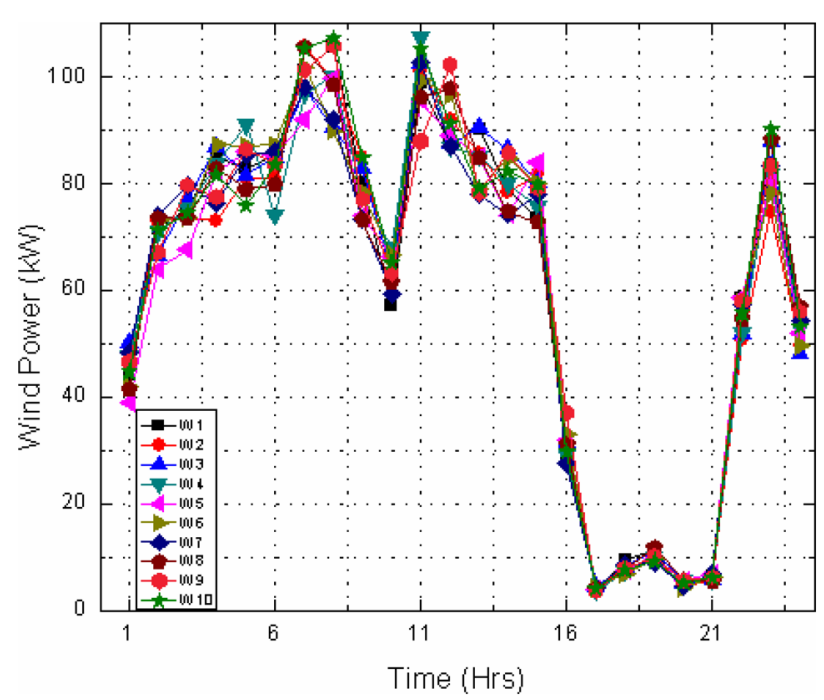

Fig. 3 Wind scenarios

found to be $\$ 152,314$ and that considering the uncertainty load was $\$ 157,460$. The rise in the generation cost was due to the rise in uncertainty load demand. Figure $7 \mathrm{a}$, b shows the load sharing between the generators when generation cost was evaluated for forecasted load and uncertainty load, respectively.

\section{Case 2: with wind support}

This case is again analysed in two different scenarios. First the forecasted wind profile is subtracted from the forecasted load and the net load thus obtained is to be shared among the three generators. Optimal scheduling was performed, and the generation cost obtained in this aspect was $\$ 110,381$. Thereafter, for the second scenario, the uncertainty load profile and uncertainty wind profile were considered. The net load 


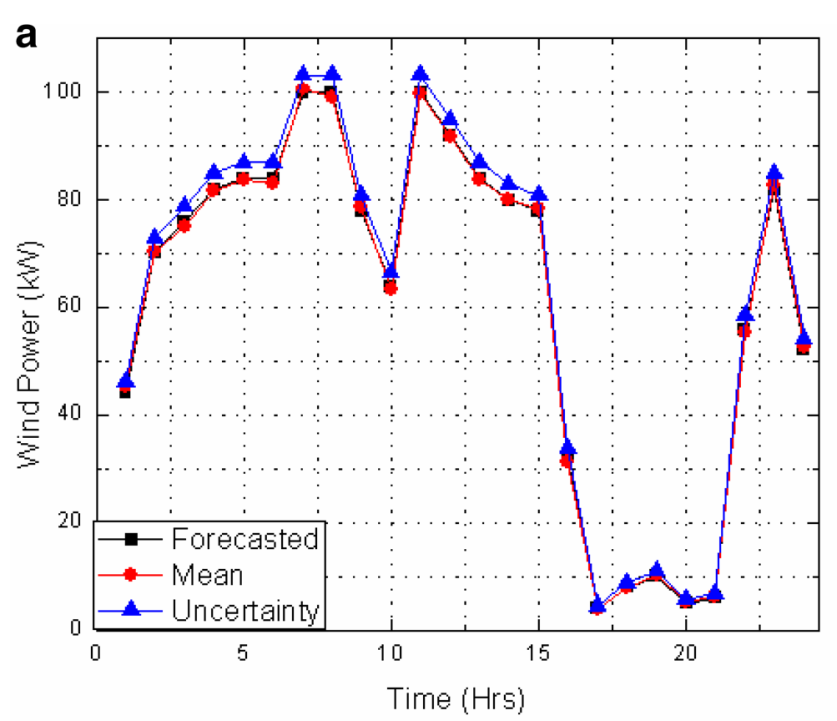

b

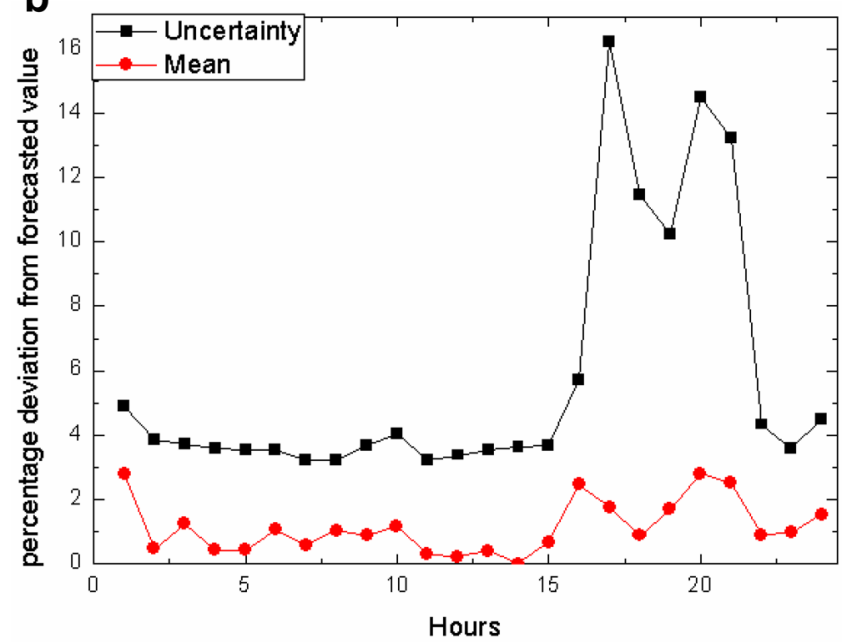

Fig. 4 a Wind profiles of forecasted, mean and uncertainty values. $\mathbf{b}$ Percentage deviation of mean and uncertainty wind profiles from the forecasted value

left after subtracting the former from the latter was to be optimally scheduled among the three generators to attain the least generation cost using proposed MGWOSCACSA. The generation cost was affected with the rise in uncertainty profile as compared to the previous scenario and rose up to $\$ 112,402$. Figure $8 \mathrm{a}$, b shows the load sharing among the generators for both the scenarios, respectively. When compared to the previous case, the dip in the generator outputs in Case 2 marks the penetration of wind power to support the conventional generators in meeting the load demands.

\section{Case 3: with wind support and unit commitment}

Unit commitment (UC) is basically assigning a minimum operating period (also known as uptime) to the generating units. A generating unit must operate for the assigned period of time. Beyond the operating period, the generating unit 'can' shut down or stay 


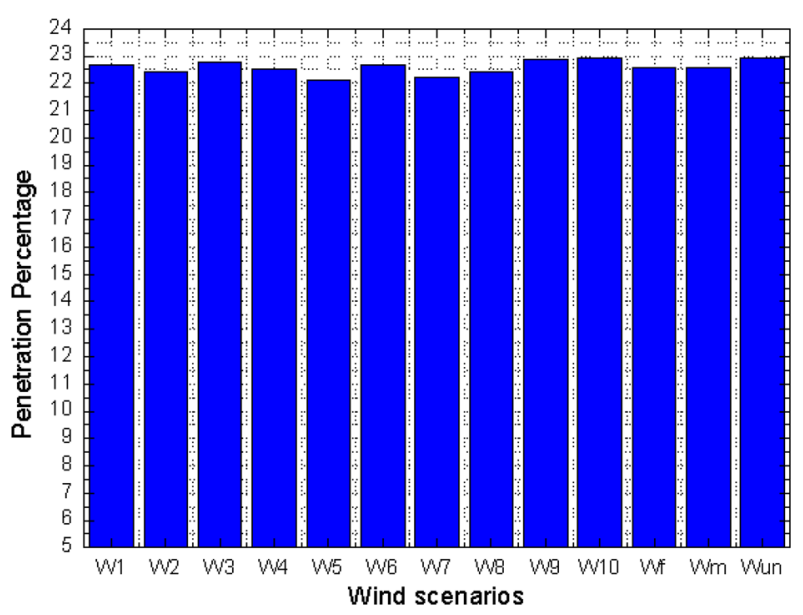

Fig. 5 Wind penetration

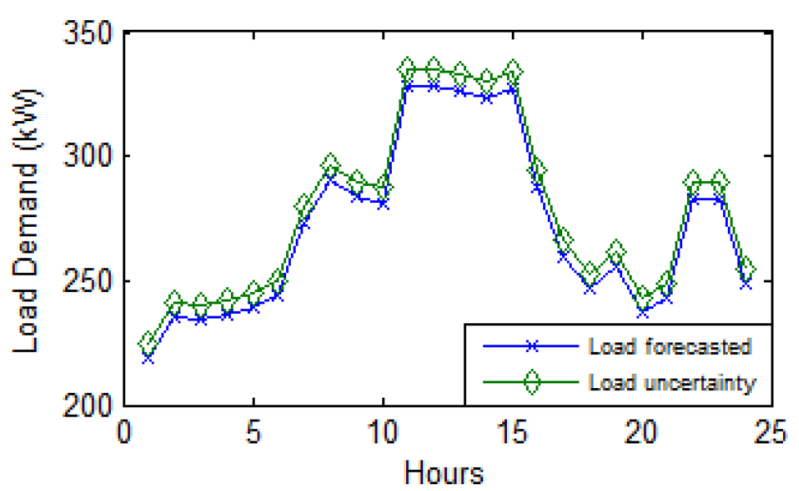

Fig. 6 Load uncertainty profile
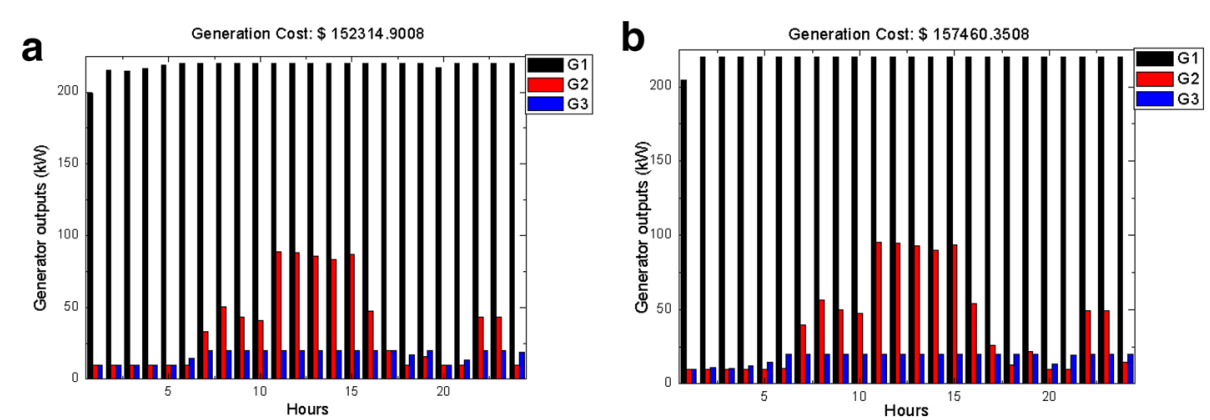

Fig. 7 Load sharing among DGs without wind support for a forecasted load profile. b Uncertainty load profile

in a standby mode if and only if the required load demand would be met in its absence. UC helps in minimizing the generation cost and pollutant emission and increase the longevity of the generating units. 

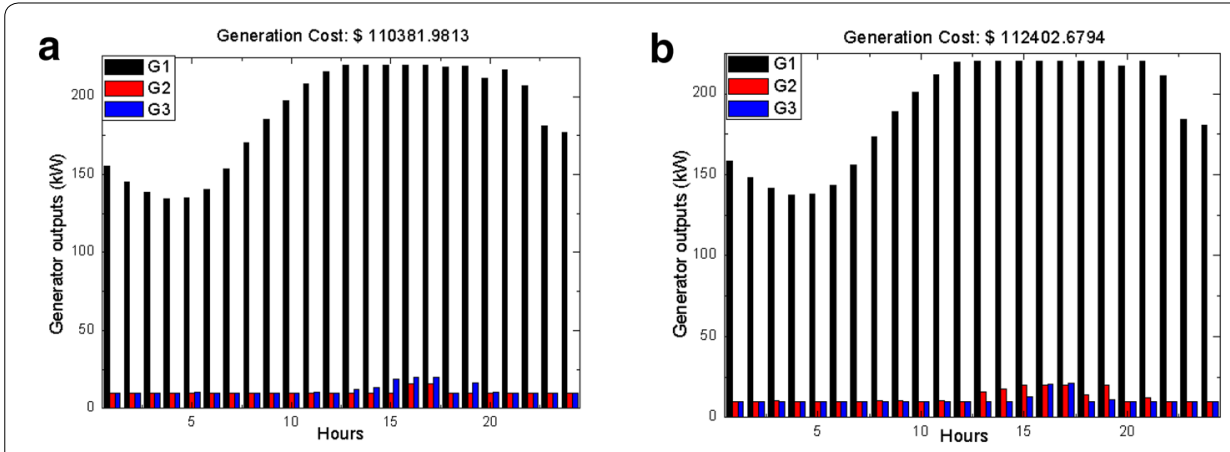

Fig. 8 Load sharing among DGs with wind support for a forecasted load profile. b Uncertainty load profile

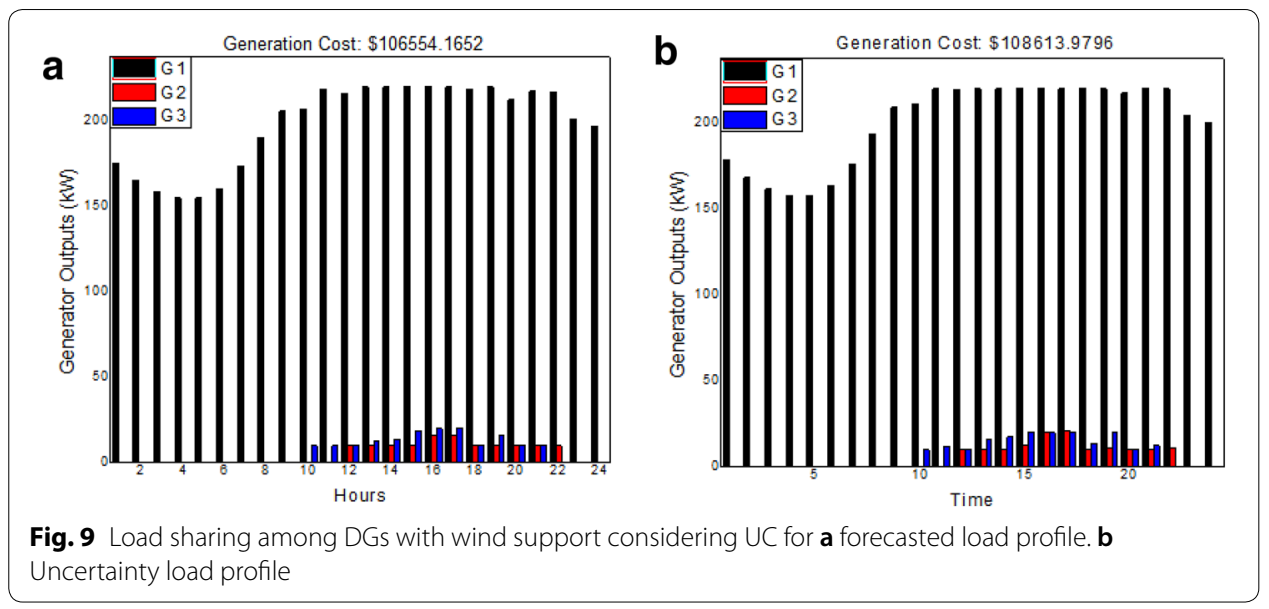

Like Case 2, two scenarios were studied for this case too. MGWOSCACSA yielded a minimum generation cost of $\$ 106,554$ for scenario 1 with forecasted load cum wind profile and $\$ 108,613$ for scenario 2 with uncertainty in load and wind profile. Figure 9a, b shows the load sharing among the generators for both the scenarios, respectively. It can be seen from the figure that generators G2 and G3 do not operate in the early hours, whereas G1 delivers power throughout the day. This is because of the increasing trend of the load demands during those hours. G2 and G3 consume higher amount of fuel as compared to G1 and are thus not operated during those hours to minimize the generation cost. The up/down status of the generators is given in Table 4 where status 1 means the generator is $\mathrm{ON}$ and 0 means OFF.

Since this is the complex case among the three cases studied, various other hybrid and modifications of GWO such as MGWO, PSOGWO, DEGWO, MGWOSCA and MGWOCSA were also implemented to perform EED on both forecasted and uncertainty values of wind and load profile. The best value obtained using various algorithms for 30 trials each is displayed in Table 4 along with the elapsed time to reach 500 iterations. Figures 10 and 11 show the convergence curve characteristics of all the algorithms implemented to perform EED on Case 3 for forecasted and uncertainty values of load profile, respectively. 
Table 4 Cost comparative analysis for EED during Case 3 using various algorithms

\begin{tabular}{|c|c|c|c|c|}
\hline \multirow[t]{2}{*}{ Algorithms } & \multicolumn{2}{|c|}{ Forecasted load and wind profile } & \multicolumn{2}{|c|}{ Uncertainty load and wind profile } \\
\hline & EED (\$) & $\begin{array}{l}\text { Elapsed time (s/ } \\
\text { iter) }\end{array}$ & EED (\$) & $\begin{array}{l}\text { Elapsed } \\
\text { time (s/ } \\
\text { iter) }\end{array}$ \\
\hline GWO & $106,611.7784$ & 1.25 & $108,655.5612$ & 1.16 \\
\hline MGWO & $106,609.1476$ & 1.66 & $108,645.8306$ & 1.08 \\
\hline PSOGWO & $106,608.7025$ & 0.73 & $108,644.0896$ & 0.99 \\
\hline DEGWO & $106,605.6591$ & 1.23 & $108,643.2715$ & 1.38 \\
\hline MGWOSCA & $106,604.8609$ & 0.70 & $108,642.7836$ & 1.21 \\
\hline MGWOCSA & $106,561.5118$ & 1.09 & $108,640.3877$ & 1.05 \\
\hline MGWOSCACSA & $106,554.1652$ & 0.65 & $108,613.9796$ & 1.05 \\
\hline
\end{tabular}
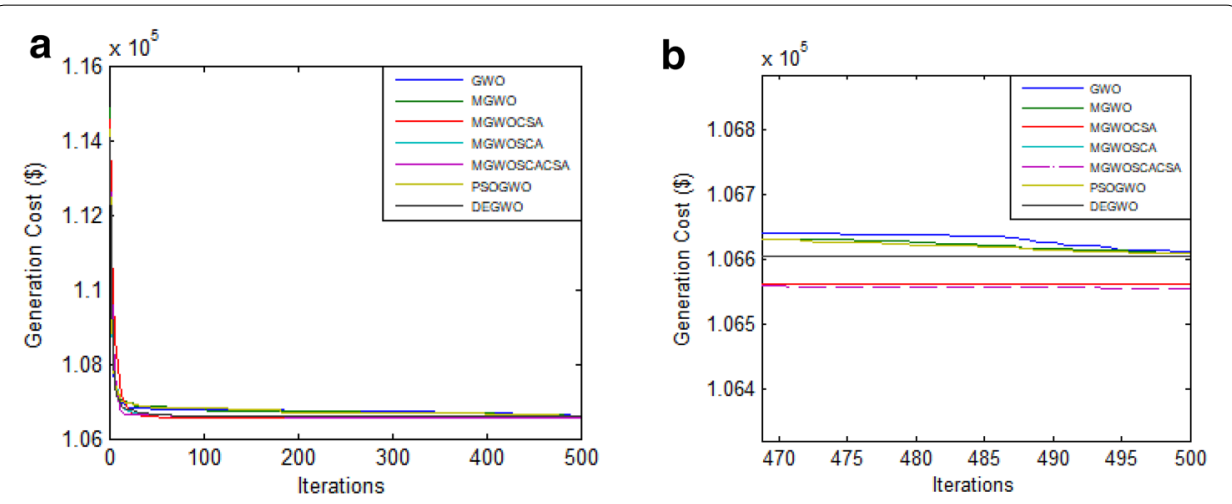

Fig. 10 a Convergence curve characteristics for EED in Case 3 with forecasted wind and load profile. $\mathbf{b}$ Magnified to differentiate the proposed algorithm

\section{Analysis of results}

When the two scenarios of the three cases were tallied among themselves, it is seen in Fig. 12 that $30 \%$ savings were attained in the generation cost when the microgrid system was powered with wind support and committed generating units compared to the case when the microgrid system was powered with generators only. Less wear and tear of rotating machines occur when they are at rest. Owing to this reason, Case 3 operating strategy is a much preferable one compared to the other two cases.

UP is the ratio of total power supplied by a DG source throughout its working hours to the maximum rated power that can be actually delivered by that DG source. Figure 13 shows the utilization percentage of the generators for the three different cases. The fuel consumption trend of the generators are G2 > G3 > G1, and hence, the utilization percentage of the generators follows the opposite trend. Furthermore, if we consider the utilization percentage of the generators w.r.t. the cases studied, then Fig. 10 shows that the UP of the generators was maximum in Case 1 and least in Case 3.

Both GWO and novel hybrid MGWOSCACSA were implemented to perform economic emission dispatch with and without unit commitment for all the ten different wind scenarios including forecasted, mean and uncertainty values of wind profile. 

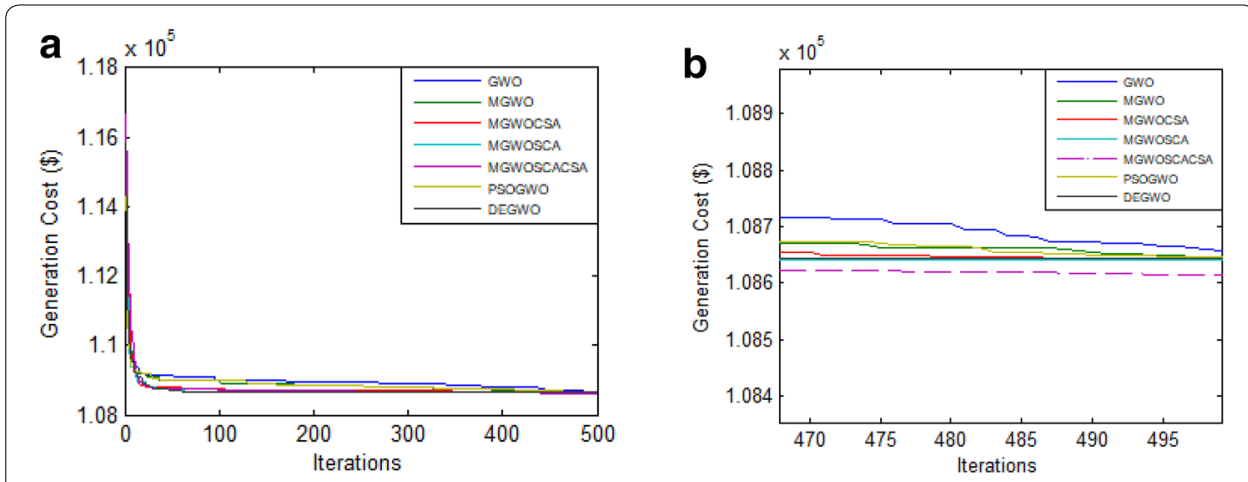

Fig. 11 a Convergence curve characteristics for EED in Case 3 with uncertainty in wind and load profile. b Magnified to differentiate the proposed algorithm

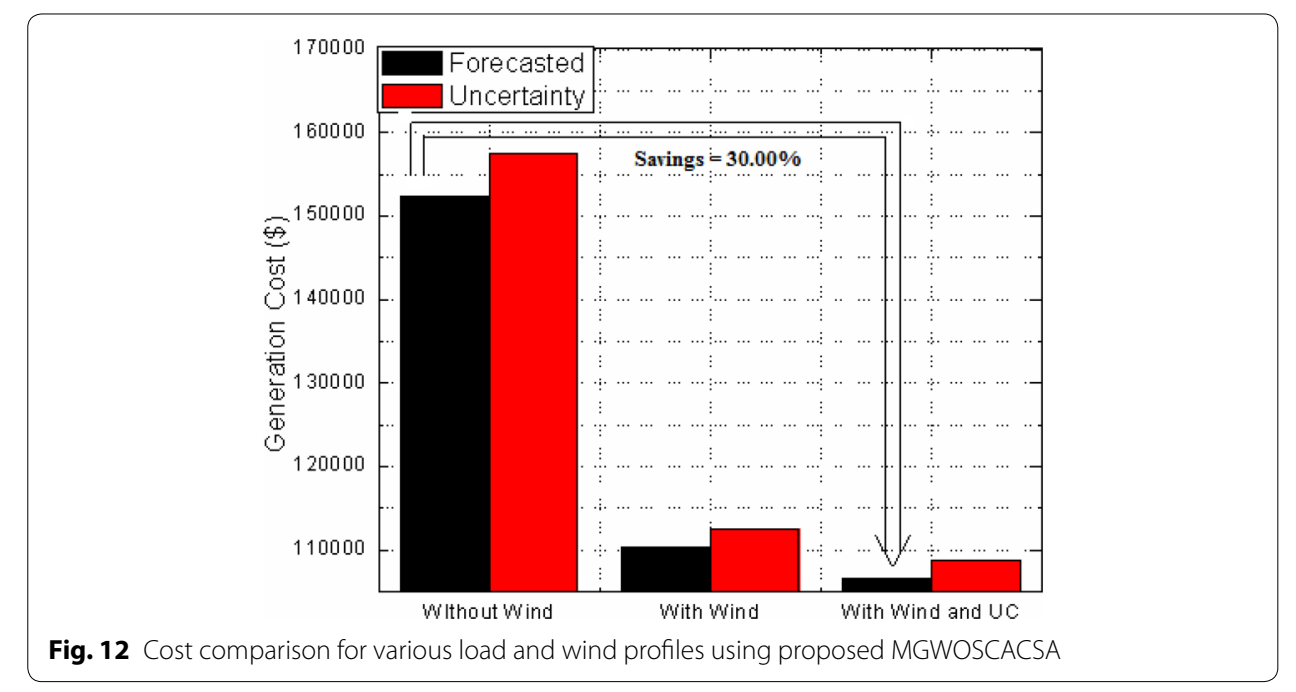

Figure 14a, b plots the various minimized generation costs obtained with and without unit commitment, respectively. It can be seen that the costs obtained in Fig. 14b maintains a lower profile than Fig. 14a. This is solely because of the potential effect of UC to bring down the generation cost up to $30 \%$ as mentioned earlier. Among the various scenarios for both the cases (with and without UC), uncertainty wind scenario incurred the maximum generation cost due to the increase in load demand. This was followed by wind scenario 7 due to the least penetration percentage and contribution in sharing the load demand.

\section{Analysis of the optimization techniques involved}

The economic emission dispatch for all the three cases using GWO and proposed MGWOSCACSA was pulled off in a MATLAB 2013 software installed in a desktop PC with Intel core i3 processor and 4 GB RAM. Both the algorithms were executed for 30 individual times for all the cases studied with population size 100 and 500 iterations. It can be already seen from the previous results that MGWOSCACSA consistently yielded better and minimized generation cost. A statistical study, viz. Wilcoxon's signed-rank test [61], was performed for the proposed hybrid optimization technique. Let $H_{0}$ be the 


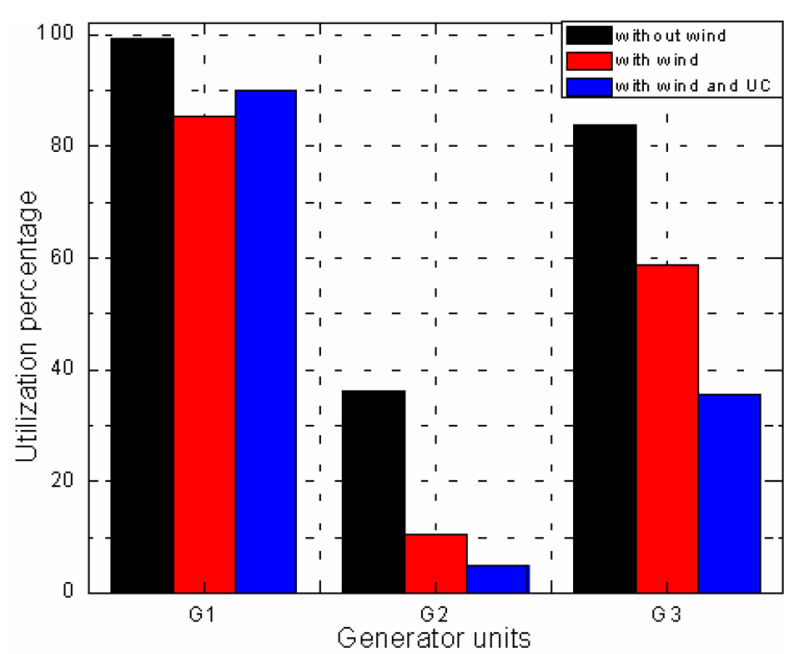

Fig. 13 Utilization percentage of generators for various load and wind profiles using proposed MGWOSCACSA
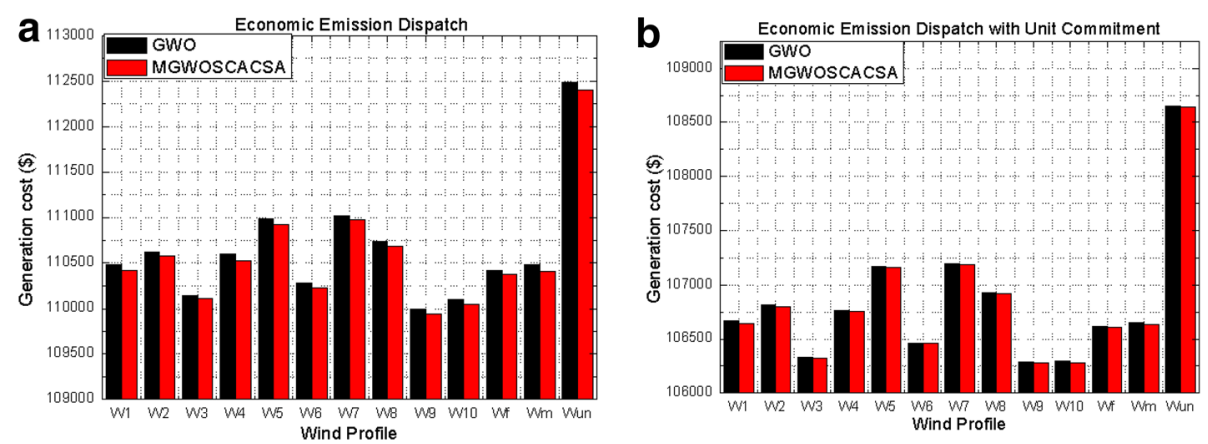

Fig. 14 EED comparison for various wind profiles a without unit commitment. b With unit commitment

hypothesis that there is no significance difference between the methods used to evaluate the generation cost and all the results discussed so far are obtained using one technique. And let $H_{1}$ be the reverse hypothesis that contradicts $H_{0}$. As per Wilcoxon's signed-rank test, if $p$ value of the superior algorithm is less than 0.05 , the hypothesis $H_{0}$ stands obsolete. Table 5 shows that the $p$ value for all the cases and scenarios studied is much less than 0.05 . This means that there are two methods involved to minimize the generation costs out of which proposed MGWOSCACSA is the superior one. Minimum value of standard deviation and maximum hits (83-96\%) to the best solution also claim the consistency and robustness of the proposed approach.

\section{Conclusion}

Economic emission dispatch was performed on a stand-alone microgrid system consisting of 3 fossil-fuelled generators and a wind turbine using GWO and proposed MGWOSCACSA. The following conclusions were reached after the study: 
Table 5 Statistical analysis of MGWOSCACSA

\begin{tabular}{llllllll}
\hline Cases & $\mathbf{S}$ & Min. cost (\$) & Max. cost $\mathbf{( \$ )}$ & Avg. cost (\$) & Hits & STD & $\boldsymbol{p}$ value (e-07) \\
\hline 1 & F & 152,314 & 152,319 & $152,314.8333$ & 25 & 1.89 & 2.5721 \\
& U & 157,460 & 157,462 & $157,460.2000$ & 27 & 0.61 & 1.4403 \\
2 & F & 110,381 & 110,382 & $110,381.0667$ & 28 & 0.25 & 1.0135 \\
3 & U & 112,402 & 112,405 & $112,402.5000$ & 25 & 1.14 & 2.5721 \\
& F & 106,554 & 106,556 & $106,555.0666$ & 28 & 0.25 & 1.0135 \\
& U & 108,613 & 108,614 & $108,613.2333$ & 29 & 1.28 & 0.6798 \\
\hline
\end{tabular}

F forecasted; $U$ uncertainty; STD standard deviation

a. The generation cost of the system without wind power was much higher than the generation cost calculated considering the wind power.

b. Relaxation in the amount of power supplied by the generators was observed upon the involvement of wind power.

c. Unit commitment-based economic emission dispatch not only decreased the generation cost to a great extent, but also helps in maintaining longevity of the generators allowing them to be at rest for 10-12 h per day. This in turn increases the reliability of the system and also decreases pollutant emitted to atmosphere.

d. For Cases 2 and 3 studied, it was seen that the generation cost considering uncertainty was about 1.9\% more than the forecasted ones. Except in Case 1 when the generation cost with uncertainty load was $3 \%$ more than the forecasted load, this again establishes the significance for involving the wind power.

e. Proposed MGWOSCACSA proved to be a superior, efficient and robust algorithm in performing economic emission dispatch problems and can be implemented for solving different power system optimization problems. High amount of elapsed time to attain the stopping criteria could be the only demerit of the proposed algorithm. This would happen when there are a large number of complex constraints to be satisfied for the decision variables or a tight range of upper and lower bounds.

As a scope to expand the future horizon of this research, test systems considering RES such as PV system and energy storage systems like battery could be included to conduct an uncertainty-based EED. Furthermore, multi-objective CEED can also be performed in larger test systems using proposed MGWOSCACSA.

\footnotetext{
Abbreviations

EED: Economic emission dispatch; UC: Unit commitment; MGWOSCACSA: Modified grey wolf optimizer-sine-cosine algorithm-crow search algorithm; GWO: Grey wolf optimizer; SCA: Sine-cosine algorithm; CSA: Crow search algorithm; ELD: Economic load dispatch; SELD: Static economic load dispatch; DELD: Dynamic economic load dispatch; DER: Distributed energy resources; RES: Renewable energy sources; ESS: Energy storage system; MRCGA: Matrix real-coded genetic algorithm; ICA: Imperialist competitive algorithm; CuSA: Cuckoo search algorithm; PSO: Particle swarm optimization; DE: Differential evolution; AMPSO: Adaptive modified particle swarm optimization; GAMS software: General algebraic modelling system; PV: Photo-voltaic; CEED: Combined economic emission dispatch; MHSA: Modified harmony search algorithm; WOA: Whale optimization algorithm; BESS: Battery energy storage system; ANN: Artificial neural network; EMS/EEMS: Energy management system/expert energy management system; CIGRE: International council on large electric systems (French: Conseil International des Grands Réseaux Électriques, CIGRÉ); DG: Distributed generation; C\&CG: Column-and-constraint generation; RMPC: Robust model predictive control; PRO: Probability-weighted robust optimization; UP: Utilization percentage; CEC: Congress on evolutionary computation; DE: Differential evolution; HS: Harmony search; PSO-GWO: Particle swarm optimization-grey wolf optimization; HGWO-RES: Hybrid grey wolf optimization-random exploratory search; MGWO: Modified grey wolf optimization; DEGWO: Differential evolution-grey wolf optimization; MGWOSCA: Modified grey wolf optimization-sine-cosine algorithm; MGWOCSA: Modified grey wolf optimization-crow search algorithm; PC: Personal computer; GB: Gigabytes; RAM: Random access memory.
} 


\section{Acknowledgements}

The authors thank Dr. Aniruddha Bhattacharya, Assistant Professor, National Institute of Technology, Durgapur, for his valuable contribution in developing the algorithm. The authors are also grateful to Nihar Karmakar, Senior Research Fellow, IIT (ISM) Dhanbad, for his constant support while preparing this article.

\section{Authors' contributions}

BD was mainly involved in coding and developing the optimization codes and implements them to attain the mentioned results and perform the literature review. SR and RB contributed in editing the article including interpretation of the results to form the tables and figures. BB supervised the manuscript. All authors read and approved the final manuscript.

\section{Funding}

Not applicable (no funding received for the research reported).

Availability of data and material

All data generated or analysed during this study are included in this published article.

\section{Competing interests}

The authors declare that they have no competing interests.

\section{Author details}

${ }^{1}$ Department of Electrical Engineering, IIT(ISM), Dhanbad, India. ${ }^{2}$ Department of Electrical Engineering, Institute of Chemical Technology Mumbai, Marathwada Campus, Jalna, Maharashtra, India. ${ }^{3}$ Department of Electrical and Electronics Engineering, Lendi Institute of Engineering and Technology, Vizag-Vizianagaram Road, Vizianagaram, Andhra Pradesh, India.

Received: 5 March 2020 Accepted: 30 August 2020

Published online: 02 October 2020

\section{References}

1. Sihna N (2001) Some studies on application of intelligent techniques to economic operation of power systems. Jadavpur University, Calcutta

2. Yalcinoz T, Short MJ (1997) Neural networks approach for solving economic dispatch problem with transmission capacity constraints. IEEE Power Eng Rev 17(10):40

3. Dhillon JS, Parti SC, Kothari DP (1993) Stochastic economic emission load dispatch. Electr Power Syst Res 26(3):179-186

4. Wang C, Shahidehpour SM (1994) Ramp-rate limits in unit commitment and economic dispatch incorporating rotor fatique effect. IEEE Trans Power Syst 9(3):1539-1545

5. Hatziargyriou N (2013) Microgrids: architectures and control

6. Luu NA (2014) Control and management strategies for a microgrid acknowledgments

7. Chen C, Duan S, Cai T, Liu B, Hu G (2011) Smart energy management system for optimal microgrid economic operation. IET Renew Power Gener 5(3):258

8. Kasaei MJ (2018) Energy and operational management of virtual power plant using imperialist competitive algorithm. Int Trans Electr Energy Syst 28(11):1-13

9. Basu M, Chowdhury A (2013) Cuckoo search algorithm for economic dispatch. Energy 60:99-108

10. Moghaddam AA, Seifi A, Niknam T, AlizadehPahlavani MR (2011) Multi-objective operation management of a renewable MG (micro-grid) with back-up micro-turbine/fuel cell/battery hybrid power source. Energy 36(11):6490-6507

11. Fan H, Yuan Q, Cheng H (2018) Multi-objective stochastic optimal operation of a grid-connected microgrid considering an energy storage system. Appl Sci 8(12)

12. Trivedi IN, Jangir P, Bhoye M, Jangir N (2018) An economic load dispatch and multiple environmental dispatch problem solution with microgrids using interior search algorithm. Neural Comput Appl 30(7):2173-2189

13. Elattar EE (2018) Modified harmony search algorithm for combined economic emission dispatch of microgrid incorporating renewable sources. Energy 159:496-507

14. Dey B, Roy SK, Bhattacharyya B (2019) Solving multi-objective economic emission dispatch of a renewable integrated microgrid using latest bio-inspired algorithms. Eng Sci Technol Int J 22(1):55-66

15. Bazmohammadi N, Tahsiri A, Anvari-Moghaddam A, Guerrero JM (2019) A hierarchical energy management strategy for interconnected microgrids considering uncertainty. Int J Electr Power Energy Syst 109(January):597-608

16. Prathapaneni DR, Detroja KP (2019) An integrated framework for optimal planning and operation schedule of microgrid under uncertainty. Sustain Energy Grids Netw 19:100232

17. Zhao T, Ding Z (2018) Cooperative optimal control of battery energy storage system under wind uncertainties in a microgrid. IEEE Trans Power Syst 33(2):2292-2300

18. Geramifar H, Shahabi M, Barforoshi T (2017) Coordination of energy storage systems and DR resources for optimal scheduling of microgrids under uncertainties. IET Renew Power Gener 11(2):378-388

19. Motevasel M, Seif AR (2014) Expert energy management of a micro-grid considering wind energy uncertainty. Energy Convers Manag 83:58-72

20. Mohan V, Suresh R, Singh JG, Ongsakul W, Madhu N (2017) Microgrid energy management combining sensitivities, interval and probabilistic uncertainties of renewable generation and loads. J Emerg Sel Top Circuits Syst $7(2): 262-270$ 
21. Kanwar N, Gupta N, Niazi KR, Swarnkar A (2018) Optimal distributed resource planning for microgrids under uncertain environment. IET Renew Power Gener 12(2):244-251

22. Nikmehr N, Najafi-Ravadanegh S (2015) Optimal operation of distributed generations in micro-grids under uncertainties in load and renewable power generation using heuristic algorithm. IET Renew Power Gener 9(8):982-990

23. Rabiee A, Sadeghi M, Aghaeic J, Heidari A (2016) Optimal operation of microgrids through simultaneous scheduling of electrical vehicles and responsive loads considering wind and PV units uncertainties. Renew Sustain Energy Rev 57:721-739

24. Zhang C, XuY, Dong ZY (2018) Probability-weighted robust optimization for distributed generation planning in microgrids. IEEE Trans Power Syst 33(6):7042-7051

25. Zhang Y, Fu L, Zhu W, Bao X, Liu C (2018) Robust model predictive control for optimal energy management of island microgrids with uncertainties. Energy 164:1229-1241

26. Aranizadeh A, Zaboli A, Asgari Gashteroodkhani O, Vahidi B (2019) Wind turbine and ultra-capacitor harvested energy increasing in microgrid using wind speed forecasting. Eng Sci Technol Int J 4-10

27. Khandelwal A, Bhargava A, Sharma A, Sharma H (2018) Modified grey wolf optimization algorithm for transmission network expansion planning problem. Arab J Sci Eng 43(6):2899-2908

28. Gupta S, Deep K (2020) A memory-based grey wolf optimizer for global optimization tasks. Appl Soft Comput 106367

29. Gupta Shubham, Deep Kusum (2019) A novel random walk grey wolf optimizer. Swarm and evolutionary computation 44:101-112

30. Gupta S, Deep K, Mirjalili S, Kim JH (2020) A modified sine cosine algorithm with novel transition parameter and mutation operator for global optimization. Exp Syst Appl 113395

31. Gupta S, Deep K, Moayedi H, Foong LK, Assad A (2020) Sine cosine grey wolf optimizer to solve engineering design problems. Eng Comput 1-27

32. Hassanien AE, Rizk-Allah RM, Elhoseny M (2018) A hybrid crow search algorithm based on rough searching scheme for solving engineering optimization problems. J Ambient Intell Human Comput 1-25

33. Rizk-Allah RM, Hassanien AE, Bhattacharyya S (2018) Chaotic crow search algorithm for fractional optimization problems. Appl Soft Comput 71:1161-1175

34. Rizk-Allah RM, Hassanien AE, Slowik A (2020) Multi-objective orthogonal opposition-based crow search algorithm for large-scale multi-objective optimization. Neural Comput Appl 1-32

35. Rizk-Allah Rizk M (2018) Hybridizing sine cosine algorithm with multi-orthogonal search strategy for engineering design problems. J Comput Des Eng 5(2):249-273

36. Rizk-Allah Rizk M (2019) An improved sine-cosine algorithm based on orthogonal parallel information for global optimization. Soft Comput 23(16):7135-7161

37. Kamboj VK, Bath SK, Dhillon JS (2016) Implementation of hybrid harmony search/random search algorithm for single area unit commitment problem. Int J Electr Power Energy Syst 77:228-249

38. Kamboj VK, Bath SK, Dhillon JS (2017) A novel hybrid DE-random search approach for unit commitment problem. Neural Comput Appl 28:1559-1581

39. Kamboj VK, Bath SK, Dhillon JS (2017) Hybrid HS-random search algorithm considering ensemble and pitch violation for unit commitment problem. Neural Comput Appl 28:1123-1148

40. Kamboj VK (2016) A novel hybrid PSO-GWO approach for unit commitment problem. Neural Comput Appl 27:1643-1655

41. Bhadoria A, Kamboj VK (2019) Optimal generation scheduling and dispatch of thermal generating units considering impact of wind penetration using HGWO-RES algorithm. Appl Intell 49:1517-1547

42. Dey B, Das P (2019) Dynamic economic dispatch of microgrid system using hybrid intelligence techniques. In: 2019 International conference on electrical, electronics and computer engineering (UPCON), pp 1-6, IEEE

43. Arora Sankalap, Singh Harpreet, Sharma Manik, Sharma Sanjeev, Anand Priyanka (2019) A new hybrid algorithm based on Grey wolf optimization and crow search algorithm for unconstrained function optimization and feature selection. IEEE Access 7:26343-26361

44. Devarapalli R, Bhattacharyya B (2020) A hybrid modified grey wolf optimization-sine cosine algorithm-based power system stabilizer parameter tuning in a multimachine power system. Opt Control Appl Methods

45. Makhdoomi Sina, Askarzadeh Alireza (2020) Optimizing operation of a photovoltaic/diesel generator hybrid energy system with pumped hydro storage by a modified crow search algorithm. J Energy Storage 27:101040

46. Singh D, Dhillon JS (2019) Ameliorated grey wolf optimization for economic load dispatch problem. Energy 169:398-419

47. Wang Jie-Sheng, Li Shu-Xia (2019) An improved grey wolf optimizer based on differential evolution and elimination mechanism. Sci Rep 9(1):1-21

48. Gupta S, Deep K (2019) Hybrid grey wolf optimizer with mutation operator. In: Soft computing for problem solving, pp 961-968. Springer, Singapore

49. Gupta Shubham, Deep Kusum (2019) Improved sine cosine algorithm with crossover scheme for global optimization. Knowl-Based Syst 165:374-406

50. Gupta Shubham, Deep Kusum (2019) A hybrid self-adaptive sine cosine algorithm with opposition based learning. Expert Syst Appl 119:210-230

51. Gupta Shubham, Deep Kusum, Engelbrecht Andries P (2020) A memory guided sine cosine algorithm for global optimization. Eng Appl Artif Intell 93:103718

52. Raj Saurav, Bhattacharyya Biplab (2018) Reactive power planning by opposition-based grey wolf optimization method. Int Trans Electr Energy Syst 28(6):e2551

53. Sawle Y, Gupta SC, Bohre AK (2018) A novel methodology for scrutiny of autonomous hybrid renewable energy system. Int J Energy Res 42(2):570-586

54. Jamshidi M, Askarzadeh A (2018) Techno-economic analysis and size optimization of an off-grid hybrid photovoltaic, fuel cell and diesel generator system. Sustain Cities Soc 44:310-320 
55. Li X, Song YJ, Han SB (2008) Frequency control in micro-grid power system combined with electrolyzer system and fuzzy PI controller. J Power Sour 180(1):468-475

56. Kumar KP, Saravanan B (2019) Day ahead scheduling of generation and storage in a microgrid considering demand Side management. J Energy Storage 21:78-86

57. Mirjalili S, Mirjalili SM, Lewis A (2014) Grey wolf optimizer. Adv Eng Softw 69:46-61

58. Mirjalili Seyedali (2016) SCA: a sine cosine algorithm for solving optimization problems. Knowl-Based Syst 96:120-133

59. Askarzadeh A (2016) A novel metaheuristic method for solving constrained engineering optimization problems: crow search algorithm. Comput Struct 169:1-12

60. Wang J, Shahidehpour M, Li Z (2008) Security-constrained unit commitment with volatile wind power generation. IEEE Trans Power Syst 23(3):1319-1327

61. Derrac J, García S, Molina D, Herrera F (2011) A practical tutorial on the use of nonparametric statistical tests as a methodology for comparing evolutionary and swarm intelligence algorithms. Swarm Evol Comput 1(1):3-18

\section{Publisher's Note}

Springer Nature remains neutral with regard to jurisdictional claims in published maps and institutional affiliations.

\section{Submit your manuscript to a SpringerOpen ${ }^{\circ}$} journal and benefit from:

- Convenient online submission

- Rigorous peer review

Open access: articles freely available online

- High visibility within the field

- Retaining the copyright to your article

Submit your next manuscript at $\gg$ springeropen.com 